Vertebrates as a whole

\section{R. McNeill Alexander}

Vertebrate Natural History. By Mary F. Willson.

Holt Saunders/Holt Rinehart \&

Winston: 1984. Pp.621. £33.95, \$37.95.

"NATURAL history" is a term that needs rehabilitation. We tend to use it only to refer to amateur field studies, and in the names of museums, but it is an excellent, succinct description for studies that deal with whole organisms rather than tissues or cells. In Vertebrate Natural History Dr Willson uses it very broadly, to refer to subject areas ranging from environmental physiology to sociobiology. She tells us that "for the modern study of natural history, it is inadequate to construct a catalog of cute little tricks employed by organisms".

The book has four parts, which are not well integrated. The first is intended to set the scene, and includes elementary introductions to evolution and allometry, a review of the vertebrates (which is little more than a catalogue of orders, without anatomical detail) and a description of the world's climates and vegetation. The second part is the physiological one, discussing senses, thermo- and osmoregulation, respiration, locomotion and migration, while the third (and shortest) deals with foraging and escape from predators. The final part covers such topics as home range and territory, courtship and mating, life history patterns and parental care.

In this book we are told about a great many aspects of the lives of a great many animals, but there is little cross-reference between one chapter and another and we are not given an integrated impression of the life of any species. The text is superficial, citing a great many investigations but providing little information about any one of them. Explanations are generally facile, without adequate reference to basic principles, and are sometimes misleading. The experimental evidence for statements is seldom given.

There are many fine drawings and photographs of animals mentioned in the text, and the chapters are headed by delightful decorative sketches, but few of the diagrams are original. In some compensation for the vagueness of the text each chapter includes a long list of generally well-chosen references - a remarkable number of the best papers of the 1960s and 1970 s are listed, but only a few from the 1980 s.

R. McNeill Alexander is Professor of Zoology at the University of Leeds.

ture to the earlier work. But the new is not simply a rehash of the old: punctuationalism is discussed, as are cladism and creationism (the last not entirely satisfactorily; but it is refreshing to find a fundamentalist correctly defined as one who adheres to the fundamentals of Christian faith), and odd snippets of information crop up which identify the book as written by someone who knows the subject rather than an intelligent hack who simply recycles existing texts. (For example, sickle cell haemoglobin homozygotes are conventially regarded as having zero fitness, but Dowdeswell describes a Saudi population where fetal haemoglobin persists into adult life and increases the fitness of sickle homozygotes apparently to unity; and the influence of plant density on the frequency of primrose homostyles is described, taking the standard story of their maintenance away from mere speculation about the effects of inbreeding.)

Evolution is a text for sixth formers and for those undergraduates arriving at university with only a tenuous grasp of the subject. It is admirably designed for that readership, as would be expected from a teacher of Dowdeswell's experience. My only grouse is that it may be too placid: will it excite current generations of A-level candidates? I don't know; I can only hope.

$R . J$. Berry is Professor of Genetics at University College London.

\section{An idea of primates}

\section{Michael Simpson}

Primate Behaviour and Social Ecology.

By Hilary O. Box.

Chapman \& Hall/Methuen: 1984.

Pp.283. f10.95, \$22.95.

THOSE who enjoy working with and reading about primates for their intrinsic interest will welcome this book as a rich vein of information and reference. Here is an uncontroversial source to complement those primate behaviour courses which concentrate upon just a few strong ideas, illustrated with a handful of examples, described in depth. It is indeed useful to have a psychologist's synthesis of approaches to "intelligent" responses to changes within social and physical environments, evident in the sections "Responsiveness and Life Strategies", "Self-awareness", "Piagetian Techniques", "The Use of Tools" and "The Question of Culture". Other kinds of material, such as Packer's study of male transfer in baboons, are well summarized for teaching purposes.

However, two caveats should be made in reponse to the book's advertisement of itself as a text for students. First, strong theoretical lines are not pursued. It could be argued that in so far as the study of primate behaviour is in a "fact-gathering hypothesis-testing" phase, this book's unfocused Aristotelian approach is appropriate, and most of the current ideas available (including so-called sociobiological ones) cannot do justice to the complex data. But a particular viewpoint can also sharpen our focus on factual material, and there is already a harvest of particular facts whose quiddity cries out for theoretical support. Why, for example, should chimpanzees and bonnet macaques be almost the only multi-male primate groups in which males groom each other extensively? Why do the daughters of so many macaque families rank socially in inverse order of their ages? Theories answering such questions could have much to say about social competition and cooperation.

My second reservation is that students will not always find that closer reading clarifies difficult passages. For instance, gender ratio adjustments in Japanese macaques (p.120) and vervet monkeys (p.233) are mentioned, but the directions of such adjustments cannot be found in the text. Fig.6.9 lacks a code for its letter symbols which would let it show "the situation clearly" (p.241). In some passages (for example p.43) the author is worsted in "the intolerable wrestle with words and meanings".

Michael Simpson is in the Medical Research Council's Unit on the Development and Integration of Behaviour at the University of Cambridge. 